\title{
PROMOTING A SPATIAL PERSPECTIVE ON PRIMARY STUDENTS THROUGH GEOTECHNOLOGIES
}

\author{
Luisa Azevedo, Vitor Ribeiro², A. Osório ${ }^{3}$ \\ ${ }^{1}$ ESEPF (PORTUGAL) \\ ${ }^{2}$ ESEPF/Minho University-Lab2PT (PORTUGAL) \\ ${ }^{3}$ Minho University-CIEd (PORTUGAL)
}

\begin{abstract}
The teaching and learning process can be enhanced by Information and Communication Technologies which became a priority in the education process. Geographic Information Systems (GIS) have the ability to deal with space and time information allowing, for example, to deeply understand location, relations or patterns. Geospatial technologies have seen an unprecedented growth in the last decade. Indeed fewer basic education schools are using them to promote spatial or technological skills. This text/research aims to discuss employability skills, attitudes and behaviours of 36 ten years old students coming from unstructured families of a deprived territory. The authors explore a practical example of the application of GIS in the teaching/learning process of primary education students. Simultaneously, the authors demonstrate the potential of those technologies to enlarge interdisciplinary analysis.
\end{abstract}

Keywords: GIS, Digital map, Teaching and Learning, Interdisciplinary, Primary education.

\section{INTRODUCTION}

Over the last two decades technology influenced the way we live, how we communicate, and how we learn [1]. According to the author learning theories "are concerned with the actual process of learning, not with the value of what is being learned".

In the last decades computer and internet technology have grown rapidly in several sectors of our modern society. GIS technology permit describe the characteristics of specified locations on the Earth's surface. Recent progresses on GIS tools simplify the process of acquire, store, analyze and share geographic information, namely through the internet [2]. Despite this growing it is recognized that there is an absence of the use of GIS in education context [3]. Yet GIS can promote interdisciplinary geography teaching and learning, since it capabilities can improve spatial analysis and spatial thinking and spatial problem solving. It is a sophisticated mapping system that can easily shift from desktop to web map representations. Education system can benefit from their capabilities to analyze several map layers to identify spatial patterns [4,5]. It can be an important invaluable resource to implement interdisciplinary projects and enhance student learning.

In 2006 the Committee on Support for Thinking Spatially strengthen that spatial thinking should be highlighted at all levels of the education curriculum. During the last decade the relationship between spatial thinking and GIS has been actively investigated [6]. GIS can promote interdisciplinary teaching and learning facilitating an understanding of the nature of geographic phenomena and information [7]. Also calls several disciplines to solve problems as a puzzle and not only as a separated element or pieces [8]. Although GIS is recognized as an essential area to embrace in initial and continuing geography teacher education can also be important on History studies. Recently geography seeks to provide students with critical spatial thinking skills, abilities and knowledge [9] where that individuals learn geography should understand that the attitudes they adopt affect the territories, making them more or less attractive, safe, efficient and fair [10]. More important than knowing the space elements, easily transmitted by expository methods, it is essential to understand the interrelationships between man and space and critically think about our actions. Thus a spatial constructivist thinking theory is an alternative method to the 21 st Century classroom by integrating pictures, videos, maps, graphics and text [11].

Bodenhamer [12] argue that geo-spatial technologies are better equipped to construct the spatial narratives and deep maps that permit, indeed encourage, the sort of reflexive, recursive, and collaborative environments that will mark history in the future. In this paper one illustrate how the web map project, developed on master education, seeks to emphasize spatial analysis, encourage to 
explore and thinking how the time phenomenon (History) were influenced by the space (geography). The complex facts of the Portuguese History can be simplified and easily understood when time and space are learned together. This interdisciplinary approach between History and Geography through GIS science provides a framework for the knowledge acquisition through exploration, reflexive and research program.

Spatial taxonomy incorporate three key elements, the concepts of space, the tools of representation, and the processes of reasoning $[13,14]$. Society is currently more global and students that acquire spatial thinking skills are better prepared to succeed in the information age and to reach some of the 21 st education skills. Over the past four decades massive progress has been made in developing and implementing tools that acquire, store, analyse, and share geographic information-that is, information describing the characteristics of specified locations on the Earth's surface. Indeed high levels of Bloom's taxonomy are reached through GIS technologies [15].

Geographic Information Systems have been recognized has an interdisciplinary tool, despite it reduced pedagogical integration [16]. Those tools have the capability to capture, store, analyse, visualize, and communicate geospatial data. Considering that interconnected information is overlapping on layers spatial analysis is possible and normally is used to understand issues, solve problems, and make spatial decisions. Due to this multiplicity and variety of data students and teachers can think on a holistic manner. Meanwhile this plethora of arguments to often integrate those tools on the curricula some barriers still prevailing among schools, namely at elementary education.

Recent internet and digital technology developments contributed to solve some of those traditional barriers. Accordingly friendly web-based GIS applications has grown faster in the last years allowing users to access maps, data and graphs over the Internet. Nowadays it is quite easiest to use those platforms permitting both instructors and students can be focused on the (inter)disciplinary content [17]. Several times the use of those technologies encourage spatial thinking naturally and manipulation of web map tools are extremely versatile and intuitive, particularly for those "digital natives" [13] [18]. This paper is a result of the accumulated experiences using Geotechnologies with elementary students through the GeoKids annual event.

\section{INTERDISCIPLINARY APPROACH TROUGH GIS PROJECT}

\subsection{Methodology}

In the $6^{\text {th }}$ annual event Geokids implemented at Higher School of Education of Paula Frassinetti (ESEPF) located in Oporto city of Portugal. This event encompass two activities and was developed in November 2015 with 36 students from an elementary school located in the same city and coming from socio deprived families. Students came from different classes, nineteen were boys and seventeen were girls including a student with special needs education and with twelve.

First activity were developed outdoor and involved two treasure hunt. Students were organized in 6 groups with 6 students each. It was developed a campus map representing the man features (buildings, water features, lamp post, garden chair, bandstand...). Map had the main elements (north arrow, scale, legend) and a grid reference were added (Figure 1). To find hunt hidden place some clues were developed to identify row and column combination and questions were related with Math and geography curriculum. Additionally students make a magnetic compass which were used to find map orientation.

Second activity were developed at ESEPF information and communication technology (ICT) classroom with two students for each computer. Students explored a Virtual Globe and a built up a dynamic map. Virtual globe were used to explore school location and neighbourhood with street view. Last challenge were used to explore students' knowledge about Portuguese Castles which is a subject located in Portuguese elementary education in the discipline of "world knowledge". Students built up a geographic database (castles geolocation castles with geographic coordinates). Attributes were collected in the Portuguese website of architectonic heritage and fulfilled in the web map (Figure 2).. Those graphic and non-graphic attributes were castles type, actual state of conservation, municipality, and pictures. Each group had 5 castles to geolocate and all students worked in the same web map. This collaborative work motivated students and challenged them not to fail.

Students were surveyed at the end of the activities to obtain their perceptions about activities and tools used during their experience. 


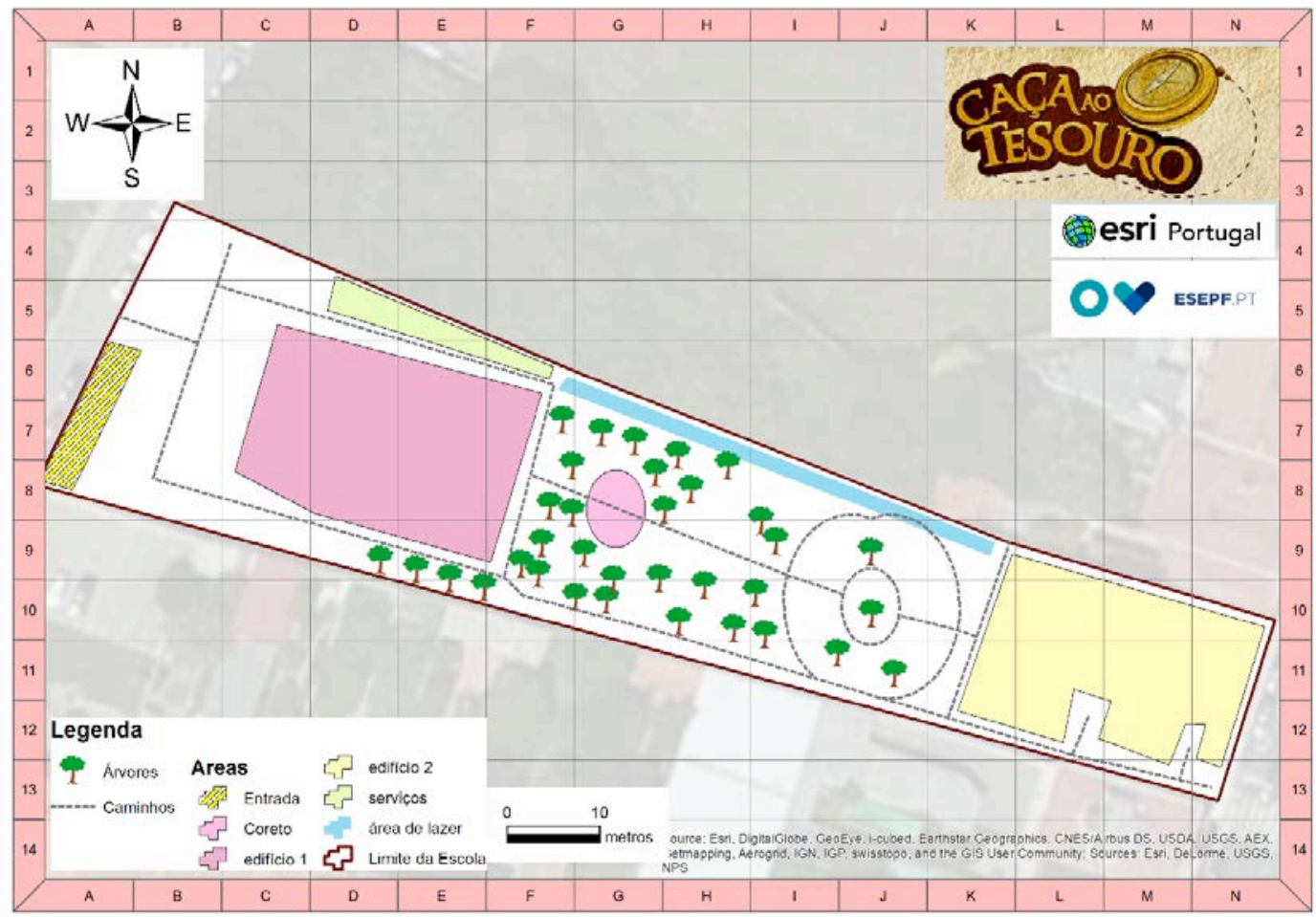

Figure 1- Hunt treasure map. Source: Authors.

INICIO V GeoKIDS: ESEPF

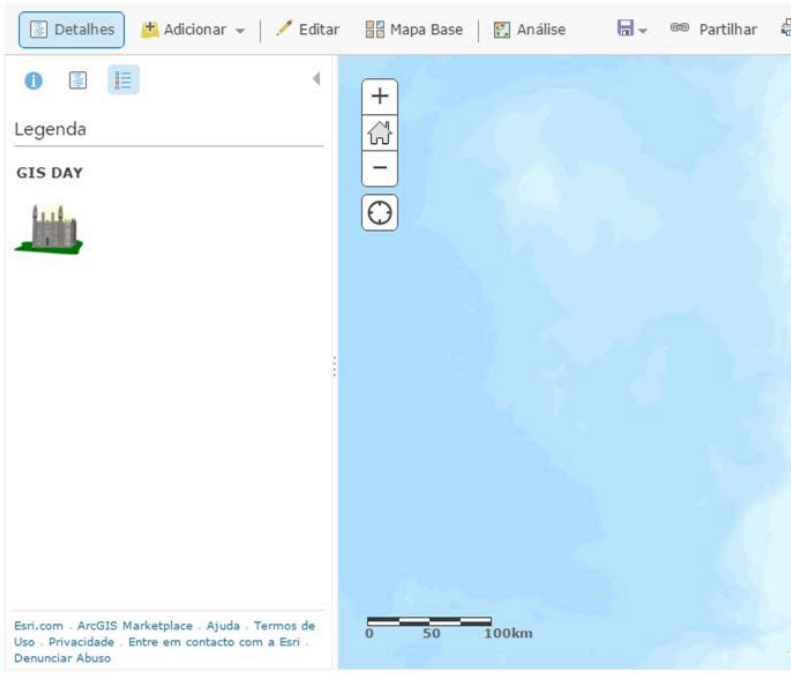

Novo Mapa Criar Apresentação vitor

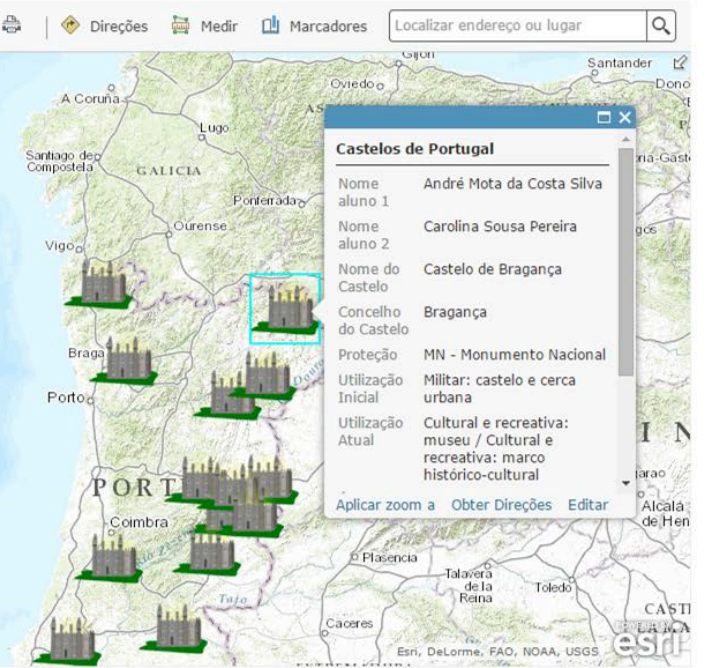

Figure 2 - Collaborative digital map layout. Source: Authors.

\subsection{Results}

Most students that participated in the GeoKids activities revealed them as an interesting, dynamic and attractive way to acquire/increase knowledge, as well as an interactive way to consolidate acquired knowledge about the cartographic representation and spatial orientation. 


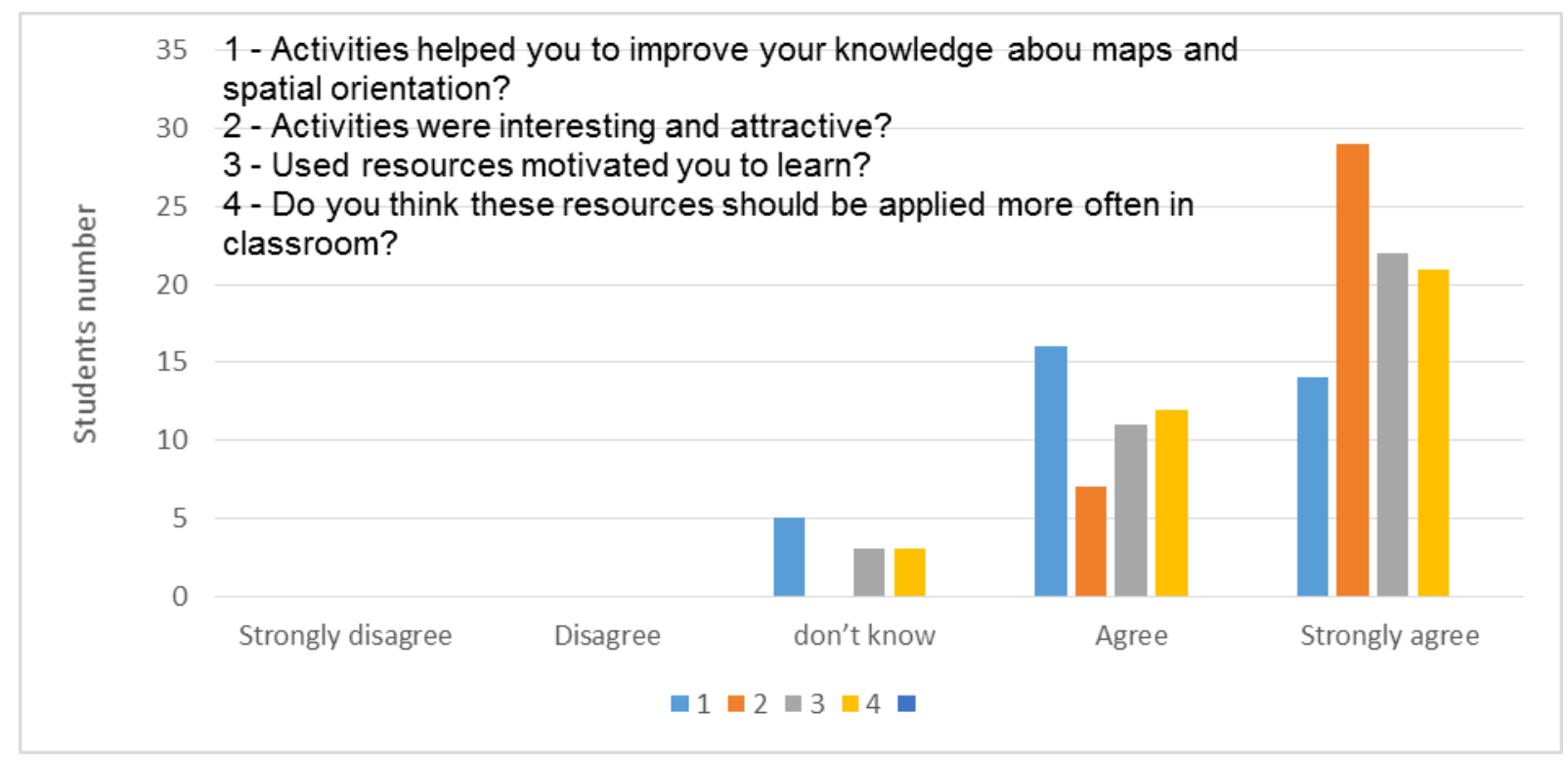

Fig. 1 - Students' perception about GeoKids activities. Source: Authors

The hunting treasure it was the less appreciated activity. Students revealed that clue questions was very simple compared with digital platforms. However we point out that one of the two hidden treasures was found by the student with special education needs. Students that appreciated first activity mentioned that constructing a compass was important to navigate over the map. The use of this geoportal allowed to explore the routes taken and the travel time required, depending on the distances covered by each of them.

Similarly to previous editions handling of geotechnology raise greater motivation, attention and interest. Virtual experiences, information control, collaborative work and digital resources manipulation were highlighted. Geocoding castles dynamically (process to locate within a set of alphanumeric entities using geographic coordinates or postal address) over the collaborative digital basemap endorsed the students to understand the location of Portuguese castles and its geographical environment (relief, natural elements or position in Portugal) and patterns.

\section{CONCLUSIONS}

Geokids activities demonstrated that elementary schools student's attitudes were affected positively by using geotechnologies. Students have had the opportunity to contact, explore, collect, share and disseminated information with geographical nature. Achieved learning experiences were considered as motivated and interested when the interconnected world of knowledge with information at our fingertips is far away from just one mouse click. An outdoor activity which promote collaborative work and challenges to adventure is undervalued when the student is placed to handle and to discover the world around us through the computer. Significant learning experiences highlights the student's perception about technology motivation and willingness to learn. Mostly they did not need a tutor to tell them how best to explore those tools during these tasks. Nevertheless using those geotechnologies in the classroom is underexplored, particularly at the elementary education.

\section{REFERENCES}

[1] Siemens, G., Connectivism: A learning theory for the digital age. 2014.

[2] Goodchild, M.F., Geographic information systems and science: today and tomorrow. Procedia Earth and Planetary Science, 2009. 1(1): p. 1037-1043.

[3] Demirci, A., How do teachers approach new technologies: Geography teachers' attitudes towards Geographic Information Systems (GIS). European Journal of Educational Studies, 2009. 1(1): p. 57-67. 
[4] Bednarz, S.W. and J. Schee, Europe and the United States: the implementation of geographic information systems in secondary education in two contexts. Technology, Pedagogy and Education, 2006. 15(2): p. 191-205.

[5] van der Schee, J., New media will accelerate the renewal of geographic education, in International handbook on geographical education. 2003, Springer. p. 205-213.

[6] Lee, J. and R. Bednarz, Components of spatial thinking: Evidence from a spatial thinking ability test. Journal of geography, 2012. 111(1): p. 15-26.

[7] Blaschke, T., J. Strobl, and K. Donert, Geographic Information Science: Building a Doctoral Programme Integrating Interdisciplinary Concepts and Methods. Procedia - Social and Behavioral Sciences, 2011. 21(0): p. 139-146.

[8] Ribeiro, V. and I.B. Monteiro. Enhancing the teaching and learning of History and Geography throught GIS: The case of routes and battles of Peninsular war (1807-1814). in 7th International Conference of Education, Research and Innovation. 2014. Seville, Spain: IATED.

[9] Bearman, N., et al., The future role of GIS education in creating critical spatial thinkers. Journal of Geography in Higher Education, 2016: p. 1-15.

[10] Gersmehl, P., Teaching Geography, ed. Edição. 2008, New York: Guilford Press.

[11] Prince Hycy, B., Using Spatial Constructivist Thinking Theory to Enhance Classroom Instruction for Students with Special Needs, in Communication Technology for Students in Special Education and Gifted Programs, E.A. Joan, F. Joy Pedego, and K.C. Judith, Editors. 2012, IGI Global: Hershey, PA, USA. p. 66-81.

[12] Bodenhamer, D., Beyond GIS: Geospatial Technologies and the Future of History, in History and GIS, A. von Lünen and C. Travis, Editors. 2013, Springer Netherlands: New York. p. 1-13.

[13] Jo, I. and S.W. Bednarz, Evaluating Geography Textbook Questions from a Spatial Perspective: Using Concepts of Space, Tools of Representation, and Cognitive Processes to Evaluate Spatiality. Journal of Geography, 2009. 108(1): p. 4-13.

[14] Shin, E.E., A.J. Milson, and T.J. Smith, Future Teachers' Spatial Thinking Skills and Attitudes. Journal of Geography, 2015: p. 1-8.

[15] Hong, J.E., Promoting Teacher Adoption of GIS Using Teacher-Centered and Teacher-Friendly Design. Journal of Geography, 2014. 113(4): p. 139-150.

[16] Ferrandino, J., Incorporating GIS as an Interdisciplinary Pedagogical Tool Throughout an MPA Program. Journal of Public Affairs Education, 2014. 20(4): p. 529-544.

[17] Baker, T.R., Internet-Based GIS Mapping in Support of K-12 Education. The Professional Geographer, 2005. 57(1): p. 44-50.

[18] Prensky, M., Digital natives, digital immigrants part 1. On the horizon, 2001. 9(5): p. 1-6. 